\title{
Unilateral antegrade cerebral perfusion using axillary venoarterial extracorporeal membrane oxygenation during central decannulation
}

Suguru Ohira, MD, PhD, David Spielvogel, MD, Steven L. Lansman, MD, PhD, and Masashi Kai, MD, Valhalla, NY

\footnotetext{
From the Division of Cardiothoracic Surgery, Department of Surgery, Westchester Medical Center, New York Medical College, Valhalla, NY.

Disclosures: The authors reported no conflicts of interest.

The Journal policy requires editors and reviewers to disclose conflicts of interest and to decline handling or reviewing manuscripts for which they may have a conflict of interest. The editors and reviewers of this article have no conflicts of interest.

Received for publication Sept 8, 2020; accepted for publication Sept 17, 2020; available ahead of print Sept 24 , 2020.

Address for reprints: Masashi Kai, MD, Division of Cardiothoracic Surgery, Westchester Medical Center, 100 Woods Rd, Valhalla, NY 10595 (E-mail: Masashi.Kai@wmchealth.org).

JTCVS Techniques 2020;4:189-92

2666-2507

Copyright (c) 2020 The Authors. Published by Elsevier Inc. on behalf of The American Association for Thoracic Surgery. This is an open access article under the CC BY-NC-ND license (http://creativecommons.org/licenses/bync-nd/4.0/)

https://doi.org/10.1016/j.xjtc.2020.09.016
}

Video clip is available online.

In postcardiotomy cardiogenic shock (PCS), central cannulation via the ascending aorta can expeditiously establish venoarterial extracorporeal membrane oxygenation (VAECMO) but has a high incidence of stroke $(17.4 \%$ $22.4 \%$ ), bleeding, and mortality. ${ }^{1-3}$ We prefer to convert to peripheral VA-ECMO to facilitate chest closure but believe that aortic decannulation poses a high risk for embolic stroke. We report our technique of unilateral antegrade cerebral perfusion (ACP) using VA-ECMO via the right axillary artery (RAX) to minimize the risk of embolic stroke during central decannulation and to confer a smooth transition to peripheral VA-ECMO.

\section{TECHNIQUE}

This study was approved by the institutional review board at the New York Medical College, with a waiver of informed consent (institutional review board approval number: \#14055 [4/14/2020]). The regional cerebral oxygen saturation is monitored. The RAX is exposed through a small infraclavicular incision, ${ }^{4}$ and, via the previous sternotomy, the brachiocephalic vessels are dissected out. An epiaortic echo is performed to evaluate the aorta, the aortic cannula, and the brachiocephalic vessels to confirm that there is no large thrombus on the aortic

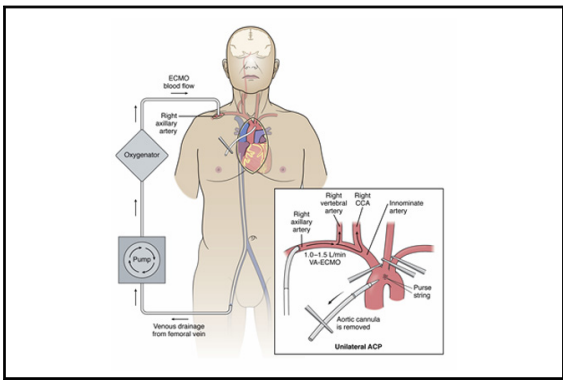

Unilateral ACP with using VA-ECMO for centra decannulation in postcardiotomy shock.

\section{CENTRAL MESSAGE \\ Unilateral antegrade cerebral perfusion using axillary venoar- terial extracorporeal membrane oxygenation can minimize the risk of embolism during central decannulation in postcardiot- omy shock.}

See Commentaries on pages 193 and 195

cannula or severe disease at clamping sites of brachiocephalic vessels.

After heparin is given (activated coagulation time $>250$ seconds), a $10-\mathrm{mm}$ graft is anastomosed to the RAX for arterial outflow. In the case of central venous cannulation, venous inflow is changed to a percutaneous femoral cannula. The left subclavian artery (LSCA) and left common carotid artery (LCCA) are clamped, and with central VA-ECMO briefly paused, the arterial line of the ECMO circuit is attached to the 10-mm RAX graft. VA-ECMO is resumed with low flow (1.0-1.5 L/min), monitoring a right radial arterial line to maintain mean arterial pressure $<60 \mathrm{~mm} \mathrm{Hg}$, and the innominate artery is clamped, thus establishing unilateral ACP (Figure 1). The aortic cannula is removed, momentarily allowing the aorta to back-flush before securing a purse string suture. The innominate artery is unclamped and ECMO flow is increased to wash the cannula site in case of potential residual thrombus (Figure 2). Finally, the LCCA and 


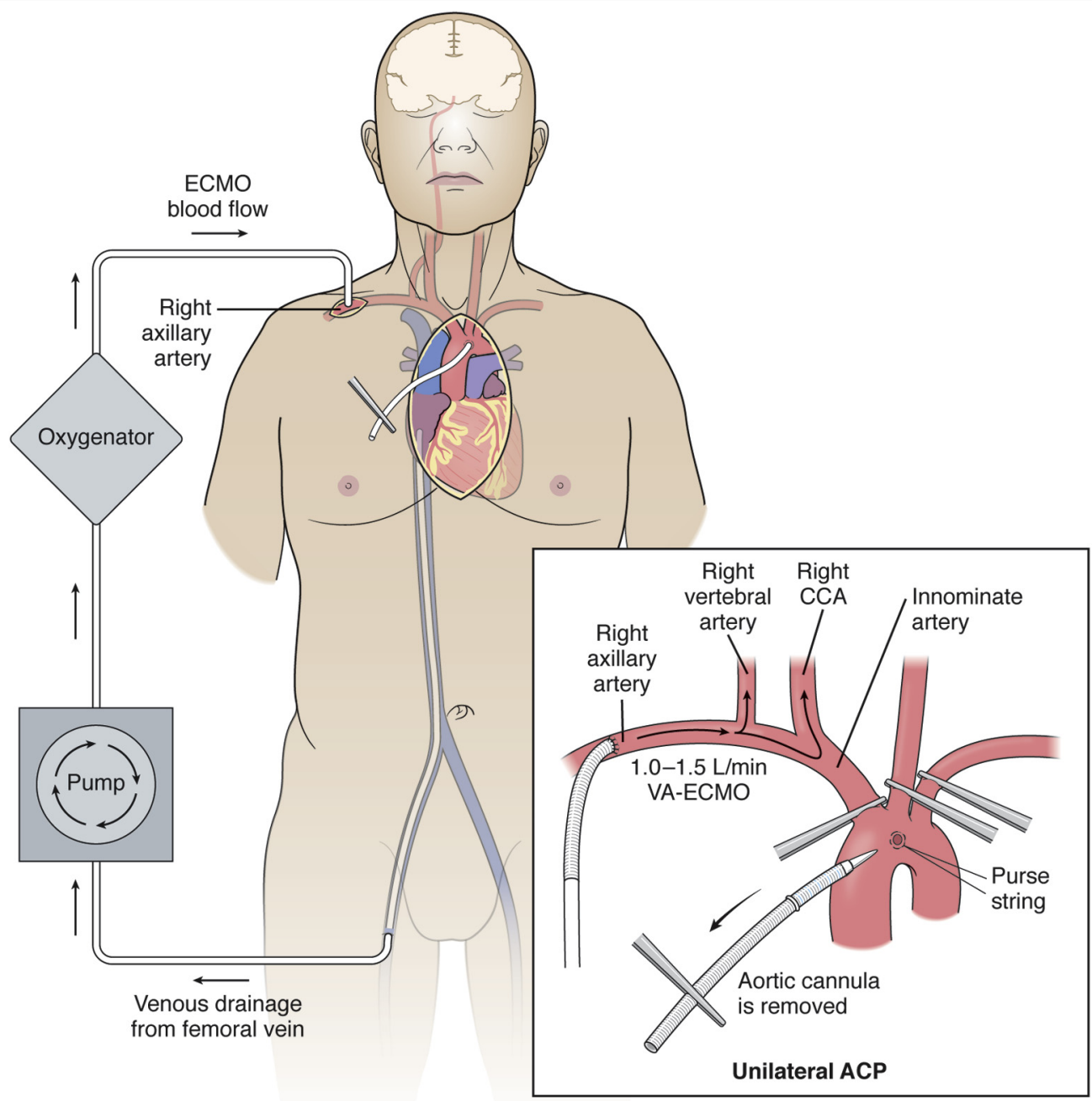

FIGURE 1. Unilateral ACP using right axillary VA-ECMO for central decannulation. The left subclavian and left common carotid arteries are clamped, and with central VA-ECMO briefly paused, the ECMO arterial line is attached to a 10-mm right axillary graft. VA-ECMO is resumed with low flow (1.0$1.5 \mathrm{~L} / \mathrm{min}$ ), maintaining mean right radial arterial pressure $<60 \mathrm{~mm} \mathrm{Hg}$. The innominate artery is clamped, establishing unilateral ACP and isolating the cerebral circulation from the cardiac ejection. ECMO, Extracorporeal membrane oxygenation; $C C A$, common carotid artery; VA-ECMO, venoarterial extracorporeal membrane oxygenation; $A C P$, antegrade cerebral perfusion.

LSCA clamps are released and full VA-ECMO flow is established. The clamping time of the LCCA and LSCA is usually less than 90 seconds.

\section{DISCUSSION}

Central VA-ECMO is an option in patients with profound PCS, as the great vessels can be expeditiously accessed. However, switching to peripheral VA-ECMO is desirable, given the greater incidence of stroke and bleeding complications related to central cannulation..$^{1-3}$ One possible source of embolic stroke during central VA-ECMO may be thrombus formation around the indwelling aortic cannula, as use of intraoperative protamine sulfate and blood products and interruption of anticoagulation may promote clot formation. ${ }^{1-3}$ If so, aortic decannulation following central VA-ECMO may pose a high risk for embolic stroke by dislodgement of thrombus that formed around the aortic cannula.

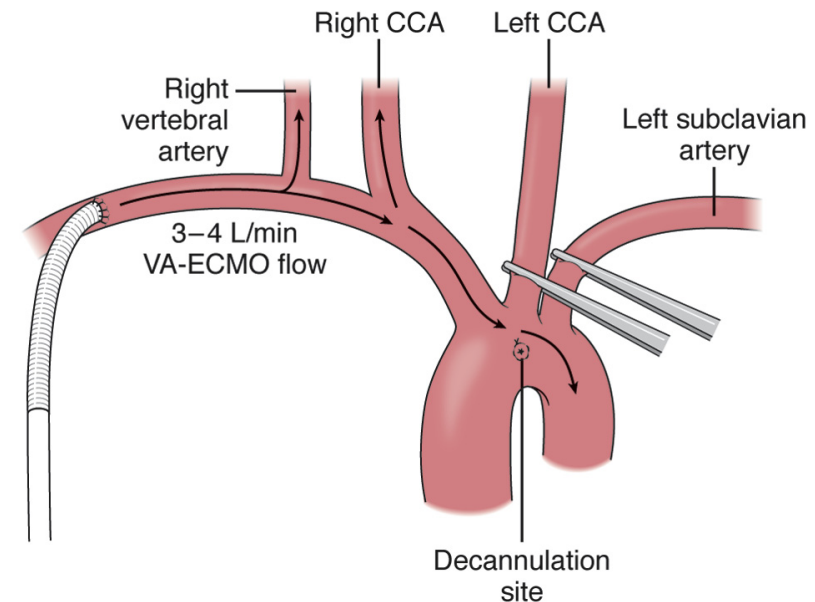

FIGURE 2. The innominate artery is unclamped while increasing VAECMO flow to flush possible residual thrombus from the central cannulation site. The left common carotid and left subclavian arteries are unclamped and full VA-ECMO flow is established. CCA, Common carotid artery; $V A-E C M O$, venoarterial extracorporeal membrane oxygenation. 


\section{Unilateral Antegrade Cerebral Perfusion Using Axillary VA-ECMO during Central Decannulation}
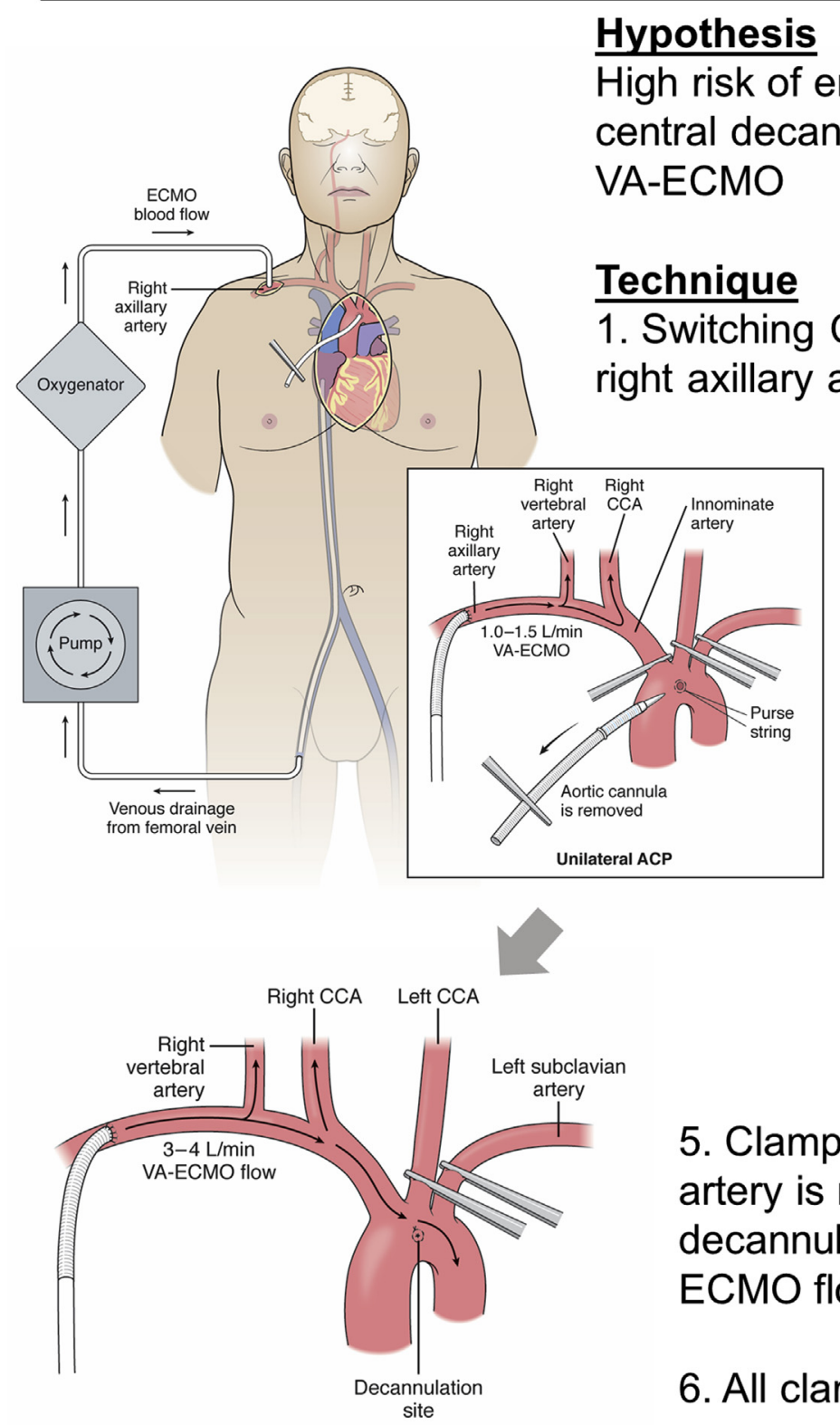

2. Left carotid, and left subclavian artery are clamped

3. VA-ECMO flow 1.0-1.5 L/min from right axillary artery, and innominate artery is clamped (Unilateral ACP)

4. Central aortic cannula is removed

5. Clamp on the innominate artery is released to flush the decannulation site (VAECMO flow: 3-4 L/min)

6. All clamps are released

FIGURE 3. ACP for stroke prevention during central ECMO decannulation. The left subclavian and left common carotid arteries are clamped, and with central VA-ECMO briefly paused, the ECMO arterial line is attached to a 10-mm right axillary graft. VA-ECMO is resumed with low flow (1.0-1.5 L/min), maintaining mean right radial arterial pressure $<60 \mathrm{~mm} \mathrm{Hg}$. With the innominate artery clamped, establishing unilateral ACP and isolating the cerebral circulation from the cardiac ejection, the aortic cannula is removed, briefly allowing the aorta to back-flush before securing a purse string suture. The innominate artery is unclamped while increasing VA-ECMO flow to flush possible residual thrombus from the central cannulation site. The left common carotid and left subclavian arteries are unclamped and full VA-ECMO flow is established. VA-ECMO, Venoarterial extracorporeal membrane oxygenation; $P C S$, postcardiotomy cardiogenic shock; $E C M O$, extracorporeal membrane oxygenation; $C C A$, common carotid artery; $A C P$, Antegrade cerebral perfusion.

The decannulation strategy described herein could minimize the risk of embolic stroke in 2 ways: first, clamping the brachiocephalic vessels at the time of decannulation prevents embolic material from entering the cerebral circulation, and second, flushing the decannulation site with antegrade ECMO flow, with the left carotid and left subclavian 


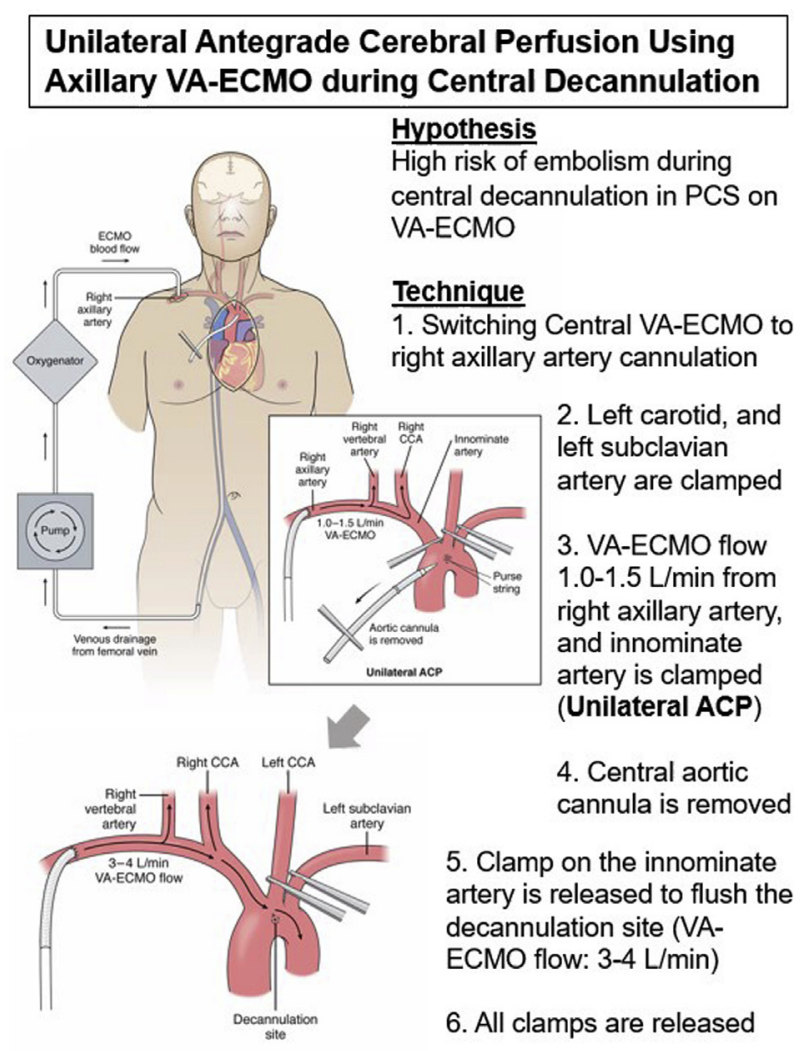

VIDEO 1. In postcardiotomy cardiogenic shock (PCS), central cannulation via the ascending aorta can expeditiously establish venoarterial extracorporeal membrane oxygenation (VA-ECMO) but has a high incidence of stroke (17.4\%-22.4\%) and mortality. One possible source of embolic stroke during central VA-ECMO may be thrombus formation around the indwelling aortic cannula, which could cause embolic stroke during its support as well as at the time of central decannulation. Indeed, we have experienced an immediate stroke after central decannulation. In this article, we report our technique of unilateral antegrade cerebral perfusion (ACP) using VA-ECMO via the right axillary artery (RAX) to minimize the risk of embolic stroke during central decannulation: First, clamping the brachiocephalic vessels at the time of de-cannulation prevents embolic material from entering the cerebral circulation. Second, flushing the de-cannulation site with antegrade ECMO flow via the right axillary artery, with the left carotid and left subclavian arteries clamped, may remove any remaining intraaortic thrombus. While doing these maneuvers, the cerebral circulation is maintained by unilateral ACP via the right axillary artery. Video available at: https://www.jtcvs.org/article/S2666-2507(20)30523-X/fulltext. arteries clamped, may remove any remaining intra-aortic thrombus. While these maneuvers are performed, the cerebral circulation is maintained by unilateral ACP via the RAX (Figure 3), which is an ideal cannulation site for this technique compared to the femoral artery. ${ }^{5}$ During unilateral ACP, we have not seen a significant drop of the regional cerebral oxygen saturation. Although exposing the LSCA is challenging in some cases, especially with a large habitus patient, we found it less difficult on VA-ECMO support, possibly because the heart is decompressed. We prefer to isolate all the brachiocephalic vessels, but this technique could be simplified by just clamping the LCCA, if exposure of the LSCA is difficult or if there is a concern for clamping the brachiocephalic vessels due to atherosclerosis. In a patient with significant atherosclerotic disease burden, manipulations of neck vessels are not recommended (Video 1).

Our representative patient was $225 \mathrm{lbs}$ and transferred to our hospital after placement of central VA-ECMO after coronary artery bypass grafting. We successfully switched to RAX VA-ECMO. He was directly transplanted off VAECMO several days later without any complications. We should note the limitation that the proposed technique has only a theoretical benefit of reducing stroke, as a large number of data are not available ( 3 patients).

In conclusion, we describe a technique of transitioning from central to peripheral VA-ECMO that uses the ECMO circuit to provide unilateral ACP via the RAX to isolate the cerebral circulation and might prevent thromboembolic stroke in patients with PCS.

\section{References}

1. Mariscalco G, Salsano A, Fiore A, Dalén M, Ruggieri VG, Saeed D, et al. Peripheral versus central extracorporeal membrane oxygenation for postcardiotomy shock: multicenter registry, systematic review, and meta-analysis. J Thorac Cardiovasc Surg. 2020;160:1207-16.e44.

2. Chamogeorgakis T, Lima B, Shafii AE, Nagpal D, Pokersnik JA, Navia JL, et al. Outcomes of axillary artery side graft cannulation for extracorporeal membrane oxygenation. J Thorac Cardiovasc Surg. 2013;145:1088-92.

3. Rastan AJ, Dege A, Mohr M, Doll N, Falk V, Walther T, et al. Early and late outcomes of 517 consecutive adult patients treated with extracorporeal membrane oxygenation for refractory postcardiotomy cardiogenic shock. J Thorac Cardiovasc Surg. 2010;139:302-11.

4. Strauch JT, Spielvogel D, Lauten A, Lansman SL, McMurtry K, Bodian CA, et al. Axillary artery cannulation: routine use in ascending aorta and aortic arch replacement. Ann Thorac Surg. 2004;78:103-8.

5. Tang GH, Malekan R, Kai M, Lansman SL, Spielvogel D. Peripheral venoarterial extracorporeal membrane oxygenation improves survival in myocardial infarction with cardiogenic shock. J Thorac Cardiovasc Surg. 2013;145:e32-3. 